\title{
CARACTERÍSTICAS MICROBIOLÓGICAS E FÍSICO-QUÍMICAS DE PESCADOS COMERCIALIZADOS EM DRACENA E REGIÃO
}

Juliana Samila de Castro Miguel, Helena Magalhães Ferreira, Bruna Graziele de Castro Miguel, Renata Tardivo, Jessica Macedo Rodrigues, Maria Luiza Poiatti

Universidade Estadual Paulista "Júlio de Mesquita Filho", curso de Zootecnia, Dracena, SP. E-mail: juliana.samila@hotmail.com

\section{RESUMO}

Os pescados são alimentos altamente perecíveis, exigindo assim cuidados especiais em seu transporte, recebimento, armazenamento, conservação e manipulação, podendo trazer alguns riscos à saúde do consumidor se não for feito um controle da qualidade do mesmo. Visando isto, objetiva-se com este trabalho verificar a qualidade do pescado por meio de análises microbiológicas e físico-químicas, de pescados comercializados por um entreposto localizado na cidade de Dracena-SP. O estabelecimento apresentou um bom padrão de qualidade dos pescados, livre de microrganismos patogênicos, garantindo a segurança alimentar ao consumidor. Os resultados foram satisfatórios visto que o estabelecimento estudado apresentou mais de $90 \%$ dos itens atendidos pela legislação.

Palavras-chave: Pescado, Segurança alimentar, qualidade.

\section{MICROBIOLOGICAL AND PHYSICAL-CHEMICAL CHARACTERISTICS OF FISH COMMERCIALIZED IN DRACENA AND REGION}

\begin{abstract}
Fish are highly perishable foods, thus requiring special care in their transportation, receiving, storage, preservation and handling, and may bring some risks to the health of the consumer if not made a quality control of the same. Aiming at this, the objective of this work is to verify the quality of the fish through microbiological and physicochemical tests of fish commercialized by a warehouse located in the city of Dracena-SP. The establishment presented a good standard of fish quality, free of pathogenic microorganisms, guaranteeing food safety to the consumer. The results were satisfactory since the establishment studied presented more than $90 \%$ of the items served by the legislation.
\end{abstract}

Keywords: Fish, food safety, quality.

\section{INTRODUÇÃO}

Conforme a definição contida do Regulamento da Inspeção Industrial e Sanitária de produtos de Origem Animal (RIISPOA) entende-se por "pescado" todos os peixes, crustáceos, moluscos, anfíbios, quelônios e mamíferos de água doce ou salgada, usados na alimentação humana.

O consumo de pescados no Brasil está aquém da expectativa por alimentos proteicos de qualidade, comparados aos dados de países como: Estados Unidos, Japão, China entre outros. Este e outros fatores provavelmente devem-se à falta de conhecimento da população sobre a importância do pescado na alimentação (CARDOSO FILHO et al., 2010). Campanhas de incentivo ao consumo de pescado são realizadas no país e, nos últimos oito anos vêm apresentando 
resultados expressivos: de $4 \mathrm{~kg}$ para $9 \mathrm{~kg} / \mathrm{ano}$ por individuo. De acordo com a Organização Mundial da Saúde (OMS), recomenda-se que o consumo per capita seja de $12 \mathrm{~kg}$ de peixe por ano por habitante, sendo que a média global de consumo per capita é de $18 \mathrm{~kg} / \mathrm{ano}$ (FAO, 2013).

Nas últimas décadas houve uma intensificação sobre pesquisas voltadas para a tecnologia alimentar. A segurança alimentar está relacionada com a presença de perigos associados aos gêneros alimentícios no momento do seu consumo. Como a introdução desses perigos pode ocorrer em qualquer etapa da cadeia alimentar, torna-se essencial à existência de um controle de qualidade.

O controle de qualidade é um importante sistema de proteção ao produto e ao consumidor, pois seu principal objetivo é assegurar a fabricação de alimento de excelente padrão e propiciar ao consumidor, um produto em condições de cumprir sua finalidade de alimentar e nutrir. Os alvos das diligências de inspeção são a matéria-prima, os equipamentos da linha de produção, a água de utilização da fábrica, os sistemas de higiene, limpeza e sanitização e o controle do produto acabado.

Portanto a qualidade do peixe fresco pode ser influenciada por equipamentos e utensílios não higienizados, superfícies contaminadas, que podem propiciar um ambiente não estéril e úmido, onde a água se acumula em cavidades e outros lugares, permitindo que grandes populações de microrganismos se desenvolvam e sejam transferidos direta ou indiretamente ao pescado (DAMS et al., 1996).

O objetivo desta pesquisa é analisar amostras de pescados congelados, processados por uma empresa do município de Dracena, com a finalidade de assegurar a qualidade microbiológica e físico-química, aos produtos distribuídos pela empresa, no estado de São Paulo.

\section{METODOLOGIA}

O presente estudo foi realizado nos laboratórios de Microbiologia Zootécnica e Bromatologia da Faculdade de Ciências Agrárias e Tecnológicas (FCAT) Unesp de Dracena. Os peixes destinados à pesquisa foram cedidos por um entreposto de pescado chegando ao laboratório de forma congelada. Os peixes utilizados para as análises Microbiológicas e Físicoquímicas foram: Filé de Tilápia (Oreochromis niloticus), Filé de Merluza (Merluccius), Filé de Polaca do Alasca (Theragra chalcogramma), Filé de Pangasius (Pangasianodon hypophthalmus. As análises da pesquisa teve início no mês de setembro, e termino em novembro do ano de 2016, com duração total de 3 meses.

\section{Análises físico-químicas}

As análises físico-químicas referentes ao $\mathrm{pH}$, umidade, matéria seca, proteína bruta e extrato etéreo foram realizadas em quadriplicatas junto ao laboratório de Bromatologia da FCATUnesp de Dracena, sendo analisadas logo após o recebimento dos peixes congelados.

\section{Determinação de pH}

Os valores de $\mathrm{pH}$ foram obtidos a partir de peagômetro digital, devidamente calibrado com soluções tampão de $\mathrm{pH} 7,0$ e 4,0. Para a determinação do pH foi usado o peagômetro (Gehaka ${ }^{\circledR}$, modelo PG 1800) equipado com eletrodo de penetração da mesma marca que fundamenta-se na medida da concentração de íons hidrogênio da amostra.

\section{Determinação de umidade e matéria seca}

Os cadinhos contendo as amostras de peixe foram devidamente identificados e colocados para secar em estufa a 105드 por 4 a 5 horas. Após esse período, pesaram-se nos cadinhos $2 \mathrm{~g}$ da 
amostra em balança de precisão (Balança Shimadzu ${ }^{\circledR}$, modelo AX200). Após esses procedimentos, os cadinhos com as amostras foram levados novamente à estufa, onde permaneceram por 12 horas a 105 ㄷ. Após esse tempo, novamente é colocado dentro do dessecador para esfriar e eliminar o restante da umidade, por 20 minutos e pesado novamente.

Cálculos:

$$
\begin{gathered}
\text { MS105 }(\%)=(\text { CAS }- \text { CV }) \times 100(\text { CAU }-\mathrm{CV}) \\
\text { CV = Cadinho vazio }(\mathrm{g}) . \\
\text { CAU = Cadinho + amostra úmida }(\mathrm{g}) . \\
\text { CAS = Cadinho + amostra seca }(\mathrm{g}) . \\
\text { Matéria Seca Natural }(\%)=\text { MS65 } \times \text { MS105 } 100 \\
\text { Umidade }(\%)=100-\% M S
\end{gathered}
$$

\section{Determinação de proteína}

A análise de proteína foi determinada pelo Método de Kjeldahl, em que $1 \mathrm{~g}$ das amostras de pescado foi pesado e colocado em tubos de digestão, adicionados $1 \mathrm{~g}$ de mistura digestora catalisadora de nitrogênio e $5 \mathrm{~mL}$ de ácido sulfúrico, que foram levados ao bloco digestor (Marconi ${ }^{\circledR}$ ). Após, houve aquecimento lento, em seguida elevado gradativamente até chegar a 350 으, em que permaneceu por 4 horas.

Posteriormente, as amostras passaram pelo destilador de nitrogênio Kjeldahl (Solab ${ }^{\circledR}$ ), para liberar amônia fixada em solução ácida. Nesse procedimento, é acoplado ao destilador um erlenmeyer contendo $20 \mathrm{~mL}$ de solução de ácido bórico $\left(\mathrm{H}_{3} \mathrm{BO}_{3}\right)$ a $4 \%$ e adaptado o tubo de Kjeldahl, adicionado $25 \mathrm{~mL}$ da solução de hidróxido de sódio $(\mathrm{NaOH})$. Após atingir $40 \mathrm{~mL}$ da solução com $\mathrm{H}_{3} \mathrm{BO}_{3}$, efetuou-se a titulação com $\mathrm{HCl} \mathrm{0,1} \mathrm{N}$ com pipetador automático (Jencons ${ }^{\circledR}$ ).

\section{Análises Microbiológicas}

As análises microbiológicas, referentes a Determinação dos Coliformes Totais e Coliformes Termotolerantes e Determinação dos Fungos e Leveduras, foram realizadas em quadriplicatas junto ao laboratório de Microbiologia Zootécnica da FCAT- Unesp de Dracena, sendo analisadas logo após o recebimento dos peixes congelados.

\section{Determinação dos Coliformes Totais e Coliformes Termotolerantes}

Para a determinação de coliformes fecais e totais foram feitas ágar MacConkey (Himedia ${ }^{\circledR}$ ) utilizando 51,5 gramas do ágar para completar $1000 \mathrm{~mL}$ de água deionizada, onde foi dissolvido e homogeneizado ao fogo em becker. Após isso, foi distribuído em Erlenmeyer de $250 \mathrm{~mL}$, para facilitar posterior plaqueamento, vedado com boneca e papel pardo e devidamente identificado. Levou-se para autoclave, onde permaneceu na temperatura de $120 \circ \mathrm{C}$ ( $1 \mathrm{~atm}$ ) por 20 minutos para a esterilização, depois desse tempo a chave comutora da autoclave foi desligada e retirou-se os Erlenmeyers contendo o ágar. Posteriormente, a câmara de fluxo laminar (Figura 4) foi higienizada e ligada, onde foi realizado todo o restante dos procedimentos com a lâmpada germicida ligada. Para a realização do plaqueamento em placas de Petri $(10 \mathrm{~cm} \times 15 \mathrm{~cm})$ foi colocado aproximadamente $15 \mathrm{~mL}$ do ágar MacConkey em cada placa, identificada corretamente e, após o ágar endurecer, levada a geladeira, onde foram utilizadas na próxima análise.

Com as diluições feitas colocadas na estufa, como descrita no tópico anterior, retiraram-se as placas de Petri contendo o meio de cultivo ágar MacConkey, levando-as para a câmara de fluxo laminar onde, com a ajuda da pipeta automática foi coletado $1 \mathrm{~mL}$ das diluições feitas (peixe mais a solução salina $10^{-1}, 10^{-2}, 10^{-3}, 10^{-4}$ e $10^{-5}$ ) e inoculada na placa com o meio de cultivo, que posteriormente foi identificado com a amostra, diluição e a data. Após esse procedimento as placas foram invertidas e levadas à estufa e por 24 - 48 horas em uma temperatura de $37^{\circ} \mathrm{C}$. 
Logo após esse período, foi realizada a contagem de UFC com o Contador de Colônias (Phoenix ${ }^{\circledR}$, modelo CP600 plus) e feita lâminas para confirmar a presença do microrganismo patogênico, pelo método de coloração de Gram descrita abaixo:

\section{Determinação dos Fungos e Leveduras}

O ágar utilizado para fazer contagem de fungos e leveduras foi o ágar Saboraud (Himedia ${ }^{\circledR}$ ) usando 65 gramas do ágar para completar $1000 \mathrm{~mL}$, como preconizado no procedimento padrão 01, novamente citado acima.

$\mathrm{Na}$ determinação da presença de fungos e leveduras foram usadas placas de Sabouraud, que também foram inoculadas todas as concentrações da solução do peixe+ água deionizada estéril $\left(10^{-1}, 10^{-2}\right.$, $10^{-3}, 10^{-4}$ e $10^{-5}$ ), realizando esse procedimento juntamente a câmara de fluxo laminar.

Após esse procedimento, as placas foram deixadas em cima da estufa, onde ficaram em temperatura ambiente, por 3 - 5 dias. Após esse período, foram realizadas as contagens das leveduras e fungo e feitas lâminas para identificação de cada um pelo método da coloração com azul de metileno a $0,05 \%$. Nesse método utiliza-se a alça de platina esterilizada no bico de Bunsen para coletar os fungos e/ou leveduras e com uma gota de azul de metileno (0,05\%) espalha-se e coloca-se uma lamínula e pode-se ser observada em microscópios as estruturas.

\section{Análise estatística}

Para a análise estatística foi utilizado um delineamento inteiramente casualizado, com 4 tratamentos e 4 repetições cada. Para comparações das médias foi utilizado o Teste de Tukey, ao nível de 5\% de probabilidade, utilizando o software R (R DEVELOPMENT CORE TEAM, 2010).

\section{RESULTADOS}

Das amostras avaliadas, até o presente momento, para a presença de coliformes totais e termotolerantes, $100 \%$ apresentaram-se em acordo com o padrão estabelecido pela legislação nacional vigente, que é $\leq 5,0 \times 10^{2} \mathrm{NMP} / \mathrm{g}$.

Ainda que a legislação não contemple a contagem de bolores e leveduras, devido à sua importância na indústria de alimentos, realizou-se o seu isolamento nas amostras analisadas. A contagem de bolores e leveduras variou entre $1,0 \times 10^{1} \mathrm{UFC} / \mathrm{g}$ e $>2,0 \times 10^{3} \mathrm{UFC} / \mathrm{g}$.

\section{Análises Físico-químicas}

Os resultados das análises físico-químicas, comparações entre as médias e coeficiente de variação, estão apresentados nas Tabelas 1 e 2.

Tabela 01. Análise de variância e coeficiente de variação para as variáveis em estudos.

\begin{tabular}{|c|c|c|}
\hline Variáveis & C.V & P- Valor \\
\hline $\begin{array}{l}\text { Umidade } \\
\text { Matéria Seca } \\
\text { Proteína Bruta }\end{array}$ & $\begin{array}{r}2,05 \\
4,56 \\
25,19 \\
10,52\end{array}$ & $\begin{array}{l}0,705^{\mathrm{ns}} \\
5,12 \mathrm{e}^{-12^{* * *}} \\
9,32 \mathrm{e}^{-13^{* * *}} \\
6,17 \mathrm{e}^{-12^{* * *}}\end{array}$ \\
\hline \multicolumn{3}{|c|}{$\begin{array}{l}\text { significativo (P-valor }>0,05) .\left({ }^{* * *}\right) \mathrm{P} \text {-valor significativo }(\mathrm{P} \text {-valor }<0,05) \text {. } \\
\text { Tabela 02. Comparações entre os resultados das médias encontradas para os pescados con } \\
\text { avaliados. }\end{array}$} \\
\hline $\mathrm{pH}$ & Umidade & Matéria Seca \\
\hline
\end{tabular}




\section{Bruta}

\begin{tabular}{ccccc}
\hline Tilápia & $6,675 \mathrm{a}$ & $80,75 \mathrm{~b}$ & $19,25 \mathrm{a}$ & $25,96 \mathrm{a}$ \\
Merluza & $6,675 \mathrm{a}$ & $80,85 \mathrm{~b}$ & $19,40 \mathrm{a}$ & $23,07 \mathrm{~b}$ \\
P. do Alasca & $6,675 \mathrm{a}$ & $87,77 \mathrm{a}$ & $12,23 \mathrm{~b}$ & $20,45 \mathrm{c}$ \\
Pangasius & $6,675 \mathrm{a}$ & $88,64 \mathrm{a}$ & $11,35 \mathrm{c}$ & $20,45 \mathrm{c}$ \\
\hline
\end{tabular}

OBS: Médias seguidas pela mesma letra nas colunas não diferem estatisticamente pelo teste de Tukey $5 \%$ de probabilidade

\section{DISCUSSÃO}

A ausência de coliformes termotolerantes é um indicativo da manipulação correta e aplicação de procedimentos de Boas Práticas de Fabricação. O grupo coliforme termotolerante compreende bactérias originárias do trato gastrintestinal de humanos e de outros animais homeotermos. Sendo assim, a presença de coliformes em alimentos processados é considerada uma indicação útil de contaminação pós-sanitização ou pós-processo, evidenciando práticas de higiene e sanitização aquém dos padrões requeridos para o processamento de alimentos (SILVA et al., 2001).

Para a legislação vigente considera-se como limites de aceitação do peixe para consumo humano o pH máximo de 6,8 (BRASIL, 1962).

Os peixes analisados apresentaram valores de $\mathrm{pH}$ considerados aptos para o consumo humano. Portanto, não houve significância estatística entre as espécies avaliadas no presente estudo.

OGAWA e MAIA (1999) citam que o músculo do pescado pode conter de 60 a $85 \%$ de umidade, aproximadamente $20 \%$ de proteína, de 1 a $2 \%$ de cinza, de 0,3 a 1,0\% de carboidrato e de 0,6 a $36 \%$ de lipídios. Este último componente apresenta uma maior variação em função do tipo de músculo corporal em uma mesma espécie (por exemplo, em atum a carne dorsal apresenta teores de 1 a $2 \%$ de lipídeos, enquanto que a carne abdominal pode alcançar até $20 \%$ ), sexo, idade, época do ano, habitat e dieta entre outros fatores.

A umidade encontrada para os filés de tilápia e de merluza apresentaram diferenças em relação aos filés de polaca do Alasca e de pangasius. Esses resultados são similares aos encontrados por SOUZA et al.(2002), que pesquisaram a qualidade físico-química de tilápia do Nilo. Esses alimentos podem ser classificados como pescados com altos teores de umidade.

Em relação ao teor de proteína encontrado nas amostras avaliadas o maior valor foi para o filé de tilápia, com 25,96g, significativamente superior ao filé de merluza, com 23,07g e para os demais, com 20,45g para os filés de polaca do Alasca e pangasius, respectivamente. Podem ser enquadrados estes produtos como importantes fontes proteicas. Esses valores encontrados foram bem superiores aos valores encontrados por Tonial et al (2010) ao estudarem o teor proteico em salmão encontraram $17,89 \%$ para o salmão in natura.

\section{CONCLUSÃO}

Os exemplares de filé de tilápia apresentaram em sua composição elevados teores de proteína, menor teor de umidade, sendo assim caracterizado como um pescado com alto teor de matéria seca e alto valor proteíco..

Embora os resultados obtidos sejam preliminares há indicação de que a manipulação pode influenciar a qualidade, ressaltando a importância de se adotar e se difundir as Boas Práticas de Manipulação - BPF e de métodos adequados de conservação durante a estocagem, visando minimizar as alterações oriundas da deterioração. 


\section{REFERÊNCIAS}

BRASIL. Ministério da Agricultura. Regulamento da Inspeção Industrial e Sanitária de Produtos de Origem Animal do Ministério da Agricultura (RIISPOA). Pescados e derivados. Rio de Janeiro, 1952.

BRASIL. Ministério da Agricultura. Decreto n.1255 de 25 de junho de 1962. Regulamento de Inspeção Industrial e Sanitária de Produtos de Origem Animal.

CARDOSO FILHO, F. C. C.; BRAGA, J. F. V.; MURATORI, M. C. S. Aspectos higiênico-sanitários de peixes comercializados em mercados públicos de Teresina, PI. Rev. Hig. Alim., v. 24, n. 183, 2010.

DAMS, R.; BEIRÃO, L.H.; TEIXEIRA, E. Prática de higiene e sanificação na indústria de pescado congelado. Revista higiene alimentar. São Paulo, v. 10, n. 44, p. 40-43, julho/agosto, 1996.

Food and Agriculture Organization (FAO). News. Disponível em: http://www.fao.org.br Acesso em: 22 out 2016.

OGAWA, M.; MAIA, E. L.; Manual de Pesca., Ciência e Tecnologia do Pescado. São Paulo, Varela, 1999, v. 1, 453 p. 17.

SILVA, M. L.; MATTÉ, G.R.; MATTÉ, M.H. Aspectos sanitários da comercialização de pescado em feiras livres da cidade de São Paulo, SP/Brasil. Rev Inst Adolfo Lutz, v.67 n.3 :208-214, 2008.

SOARES, K. M. P.; GONÇALVES, A. A. Qualidade e segurança do pescado. São Paulo: Rev inst Lutz. v.71, n.1, 2012.

SOUZA, M. L. R. Comparação de Seis Métodos de Filetagem, em Relação ao Rendimento de Filé e de Subprodutos do Processamento da Tilápia-do-Nilo (Oreochromis niloticus). Revista Brasileira

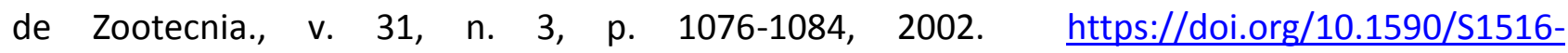
$\underline{35982002000500003}$ 